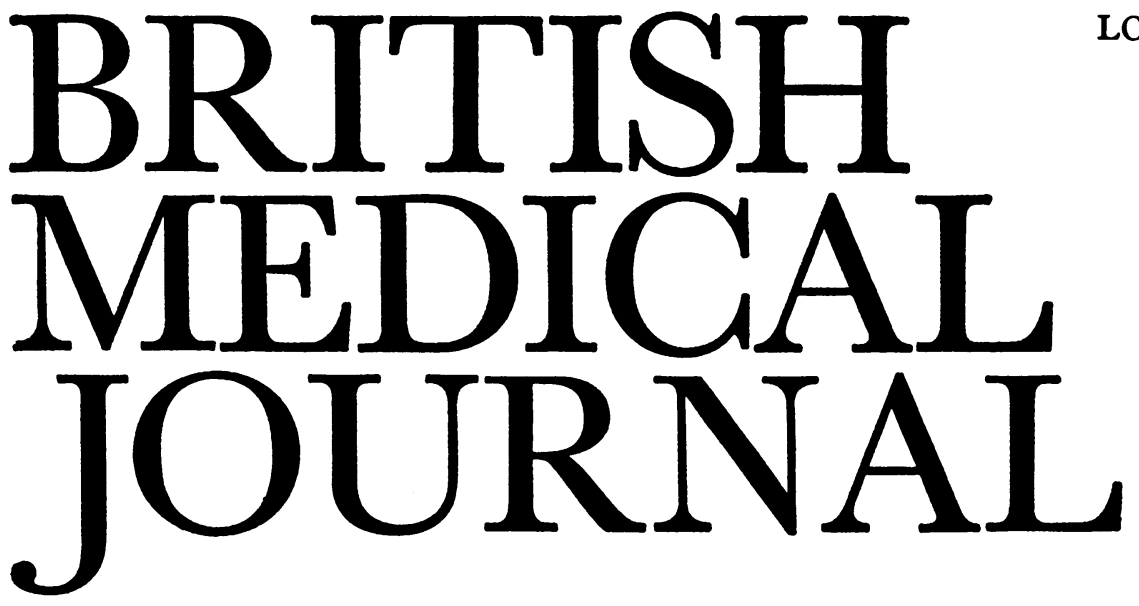

LONDON SATURDAY 7 SEPTEMBER 1974

\title{
Halothane and Liver Damage
}

The Medical Assessor to the Committee on Safety of Medicines recently issued" a letter entitled "Jaundice following repeated exposure to halothane," in which he noted that 130 reports of jaundice following anaesthesia had been received by the committee between 1964 and 1972, every case being associated with the use of halothane. Ninety-four of these patients had been exposed to halothane more than once. The assessor referred to the paper ${ }^{2}$ by Inman and Mushin which analysed these reports, and he accepted as established that multiple exposure to halothane carries a greater risk of jaundice than a single exposure, with the suggestion that repeated exposure within a few weeks may carry a greater risk, though no particular time interval was necessarily critical. This "additional evidence" was accepted by him and the letter circulated so that anaesthetists could be better able to assess all the relative risks of various agents in the clinical circumstances of each case.

The results of the assessor's letter have perhaps not been quite up to his expectations. Far from enabling anaesthetists to put the risk of liver damage into perspective, the new information has had at least two unfortunate effects. It has thrown open the question of negligence if an anaesthetist is faced with the occurrence of postoperative jaundice when he has given the patient more than one halothane anaesthetic within four weeks. It has led local ethical committees to forbid clinical trials designed to investigate the role of halothane in postoperative jaundice; in one centre such a trial was terminated. The time has, therefore, come to look impartially at the available evidence to try to distinguish fact from hypothesis and opinion.

Despite numerous scientifically valid experiments on animals in which no direct liver toxicity was shown, halothane has been under suspicion as a hepatotoxic agent since its introduction, simply because it is a volatile halogenated hydrocarbon metabolized by the liver. The term "halothane hepatitis" has commonly been used without adequate diagnostic criteria for the condition, and indeed this label has been applied in all cases by the process of exclusion of other recognized causes. Sporadic cases of jaundice, death from hepatic necrosis, and hepatorenal syndrome have been reported for more than $\mathbf{5 0}$ years, and almost no anaesthetic agent, local or general, has been excluded from blame. The National Halothane Study ${ }^{3}$ retrospectively examined 856,515 general anaesthetics which had been given over a four-year period and reported a critical and expert examination of the data. The incidence of hepatic necrosis was highest in relation to the use of cyclopropane but virtually the same for halothane as for all other anaesthetics. Later reports did not question these findings, and it can be accepted as established that single exposures to anaesthesia for minor and major surgery in the young and the old, the sick and the healthy, carry a risk of death from hepatic necrosis the causation of which, in the light of existing knowledge, cannot be related to the anaesthetic used. If halothane happens to have been used then there is at present no scientific justification for a diagnosis of halothane hepatitis, since the anaesthetic drug is related to the event in a purely random fashion. Nevertheless in Britain, where halothane is used in some $78-80 \%$ of operations, this attribution will no doubt continue despite all the evidence against it.

The National Halothane Study reported that the overall incidence of hepatic necrosis was considerably higher after two or more surgical operations in the same or successive months and that nine deaths occurred after repeated exposure to halothane. In these nine cases no explanation other than anaesthesia could be found in view of the impossibility of differentiating drug-induced liver necrosis from viral hepatitis by clinical signs or by the histological appearance of the liver.

Mushin, Rosen, and Jones, ${ }^{4}$ using data from reports to the Committee on Safety of Medicine, decided that there was a significant association between the occurrence of post-halothane jaundice and the administration of halothane within the previous four weeks, though their statistical basis has recently been questioned. ${ }^{5}$ The recent Inman and Mushin paper deduced a cause-and-effect relationship between multiple exposure to halothane and jaundice on the basis that the rapidity of onset of jaundice was related to the number of exposures-a deduction which B. McPeek and J. P. Gilbert in their article at p. 615 find questionable. Our correspondence columns have offered so much valid and pertinent criticism of the Inman and Mushin paper that the question of a cause-and-effect relationship must be regarded as still open. Nevertheless the probability remains that the repetition of exposure to anaesthetics and surgery within a few weeks is associated with a significantly higher incidence of hepatic damage than are single exposures.

Neither Professor Mushin nor the medical assessor posed the crucial question, "Is it more dangerous to repeat halothane 
than to repeat other anaesthetics within short periods ?" but left it to be assumed that this was not in question, though no data exist by which the point could be answered-with the unfortunate outcome which we have noted. The statement ${ }^{6}$ by the Medical Research Council restores some balance to the situation and the council seeks to support research designed to answer this question. The problem will not be resolved easily, since a lengthy list of possible contributing factors will have to be considered in designing an effective prospective trial.

Those with responsibility for ethical consent to clinical research should not themselves prejudge an issue so clearly unclear in an endeavour to protect the public from one speculative danger while simultaneously favouring the use of anaesthetics other than halothane-which can carry greater overall intrinsic dangers for patients.

\footnotetext{
Mansell-Jones, D., CSM/AR/S/121, 3 January 1974.

2 Inman, W. H. W., and Mushin, W. W., British Medical fournal, 1974, 1, 5.

3 Bunker, J. P., et al., The National Halothane Study. Washington, U.S. Government Printing Office, 1969.

4 Mushin, W. W., et al., British Medical fournal, 1971, 2, 18.

5 Robson, J. G., and Norman, J., British Medical fournal, 1974, 1, 516.

British Medical fournal, 1974, 3, 268.
}

\section{Hair of the Dog}

Everyone will have come across the chap in the saloon bar who insists that the only cure for a hangover is a stiff drinka hair of the dog that bit you. An American gastroenterologist, J. R. Hoon, has recently investigated this bar-room myth using a gastrocamera and two volunteers who were undergoing repeated endoscopy in the course of another study. His interest was aroused by a young man who turned up one morning after an alcoholic binge saying "if my stomach looks like my eyeballs, you are really going to see something!" Having noted an excess of gastric mucus and increased motility, Dr. Hoon was not content merely to admire the view and decided to administer gin. Within a few minutes the stomach had relaxed and was much easier to examine. Unfortunately, there appears to be a shortage of volunteers with hangovers in Wisconsin and it was six years before the study could be continued; another young man was found to have a disturbed and jumpy stomach which was calmed by whisky. However, it was not clearly stated that the hangover symptoms improved, and the mechanism of action of the alcohol was not investigated, so the gastrocamera findings must continue to tantalize the drinking public until they are confirmed.

Before every alcoholic reaches for another bottle in the morning he should be reminded that endoscopic appearances may bear no relation to clinical symptoms. This is certainly true of gastritis-a word conspicuously absent from the American paper, which is all the more surprising since alcoholic gastritis is usually assumed to be the underlying gastric lesion in inebriates. However, the omission may have been a master stroke; because the mere mention of gastritis to gastroenterologists is a recipe for a heated emotional disagreement. Transient alteration in secretion, congestion, and ready bleeding were noted by Wolf and Wolff ${ }^{2}$ in Tom's gastric fistula-appearances which could well be interpreted as gastritis but in this case were induced by feelings of hostility and resentment. Furthermore it is unlikely that any two endoscopists would agree on the presence or absence of gastritis, and it is even less likely that a pathologist would confirm their findings. Perhaps we should be looking at changes in mucus secretion and motility instead.

A word of caution must also be given to all those would-be investigators who are reaching for their endoscopes. It is now common practice to give intravenous diazepam as premedication. Unfortunately, young men who are regular heavy drinkers are more than usually resistant to this drug; when the dose is increased they merely become more uncooperative and less inclined to follow the examiner's instructions. One of the major contra-indications to endoscopy may, therefore, be a steady alcoholic intake of more than four pints $(2 \cdot 21)$ of beer per day. Such patients are often powerfully built, owing to manual labour, and young enough to retain strong teeth. They are the most frequent cause of the common but unpublicized complication of endoscopy, damage to the fibrescope.

1 Hoon, J. R., fournal of the American Metical Aswociation, (1974), 229, 184
2 Wolf, S., and Wolf, H. G., Human Gatric F',!cti ".. London. Oxford University Press, 1947.

\section{Women in Medicine}

The first woman to qualify in medicine in Britain was Elizabeth Garrett, who obtained the diploma of the Society of Apothecaries in 1865. The universities lagged behind in the admission of women to medical degrees, but Edinburgh awarded a degree to Sophia Jex-Blake in 1876. By this time the General Medical Council had accepted women as registered medical practitioners, ${ }^{1}$ and it is worth recalling that the vote for women and their eligibility to sit in Parliament did not come until 1918 , and even then they had to be over 30 years of age and fulfil certain conditions. Changes in the social order take time and a receptive climate of opinion to make them acceptable.

The persistence of generations of women is getting them ever closer to equality of status and opportunity with men in medicine (and other professions). There is still some inequality, but it seems to be diminishing. In 1973 figures from the Universities Central Council on Admissions (U.C.C.A.) ${ }^{2}$ showed that $32 \%$ of those accepted to read for medicine were women compared with only $21 \%$ in 1966 . Recently feminists and others have argued that the proportion of women reading medicine should be $50 \%$, and deans have been criticized for operating a quota system. There is no evidence to support this charge. In $197230.5 \%$ of all home candidates applying for medicine were women. Over the whole country this does not suggest sex discrimination but it does argue that there may be preselection in schools. As the numbers of women applying to medical schools has increased the deans have responded by taking more of them, and in the proportion in which they apply. No one who understands the U.C.C.A. system would believe that any dean would be so devious as to work out the proportion of female applicants beforehand and adjust his or her entry to suit.

In the past it might have been possible to argue that women were not physically or emotionally capable of dealing with the horrors of medicine and particularly surgery. Miss Nightingale's nurses in the Crimea must have helped to shatter those illu- 